\title{
УOBOЗНАВCTBO. ПUTEPATУРOЗНАВCTBO
}

\author{
УДК 81'25 \\ DOI https://doi.org/10.24919/2308-4863/35-7-2
}

\begin{abstract}
Анастасія АКІМОВА, orcid.org/0000-0001-8016-4555 магістрант кафедри теорії та практики галузевого перекладу Херсонського національного технічного університету (Херсон, Україна) akimova.18.01.1999@gmail.com
\end{abstract}

Наталя КУДРЯВЦЕВА, orcid.org/0000-0001-7641-9543 доктор філологічних наук, професор кафедри теорії та практики галузевого перекладу Херсонського національного технічного університету (Херсон, Украӥна) natkudriavtseva@gmail.com

\section{ВІДТВОРЕННЯ КУЛЬТУРНО-СПЕЦИФІЧНОЇ ІНФОРМАЦІЇ ПРИ ПЕРЕКЛАДІ ТЕХНІЧНИХ БРОШУР І СПЕЦИФІКАЦІЙ}

\begin{abstract}
У статті розглядається культурно-специфічна інформаџія в технічних текстах, а також особливості ї̈ відтворення при перекладі технічних брошур і технічних специфікацій з англійської мови українською. Розглянуто такі поняття, як «технічний текст», «специфікація», «технічна брошура». Визначено різновиди культурноспециифічної інформації, наявної в технічних текстах, а також в технічних специфікаціях і брошурах зокрема. Схарактеризовано способи відтворення культурно-специфічної інформації, щчо застосовуються при переклад $i$ технічних брошур і специфікачій з англійської на украӥнську мову. Визначено, щзо способом, який використовується найчастіше, є пошук вже наявного відповідника в цільовій мові, який застосовується у відповідних контекстах як еквівалент тієї чи іншої культурно-специфічної одиниці. Застосування зазначеного способу доречне у випадку перекладу одинииь вимірювання та абревіатур. Поряд з иим також застосовуються такі перекладацькі трансформації, як додавання і вилучення, які передбачають модифікацію або иілковите вилучення культурно-специфічної інформації, щзо релевантно при відтворенні національних стандартів. У підсумку встановлено, щчо, окрім локалізації як основного підходу до перекладу технічних текстів, використовується також інтернаціоналізація з огляду на те, щзо одним із найскладніших аспектів технічного перекладу є відтворення одиниць вимірювання, пошук відповідників до вузькогалузевих національних термінів та врахування жанровостилістичних особливостей зазначених типів текстів. Установлено, щео перекладач виступає посередником як між мовами, так і між культурами краӥн мови оригіналу та мови перекладу, тому надзвичайно важливим є ретельний підхід до аналізу обраних мов та культур у певній сфері діяльності задля виконання адекватного відтворення тексту оригіналу.
\end{abstract}

Ключові слова: технічний текст, локалізачія, інтернаціоналізація, специффікація, технічна брошура.

Anastasiia AKIMOVA,
orcid.org/0000-0001-8016-4555
Master Candidate at the Department of Specialized Translation Theory and Practice
Kherson National Technical University
(Kherson, Ukraine) akimova.18.01.1999@gmail.com
Natalia KUDRIAVTSEVA,
orcid.org/0000-0001-7641-9543
Doctor of Philological Sciences,
Professor at the Department of Specialized Translation Theory and Practice,
Kherson National Technical University
(Kherson, Ukraine) natkudriavtseva@gmail.com




\section{TRANSLATING CULTURE-SPECIFIC INFORMATION IN TECHNICAL BROCHURES AND TECHNICAL DATA SHEETS}

The article analyses culture-specific information in technical texts, as well as the specifics of its rendering in translating technical brochures and technical data sheets from English into Ukrainian. We consider such notions as "technical text", "technical data sheet", and "technical brochure". We determine the types of culture-specific information used in technical texts, as well as in technical brochures and technical data sheets, in particular. Of special significance are techniques of reproducing culture-specific information in translation of technical brochures and technical data sheets, which are characterized as relevant for English-Ukrainian translation. It is determined that one of techniques that is used most often is the search for a corresponding unit in the target language. The use of this technique is considered to be appropriate when translating measurement units and abbreviations. Among other techniques, there are such transformations as addition and deletion of information, which entail a modification or a complete omission of a culture-specific unit. This is deemed to be relevant in translation of national standards. Our findings suggest that, in addition to localization as the main strategy employed in translation of technical texts, such strategy as internationalization is also appropriate. The reason for this lies in the fact that one of the most difficult aspects of technical translation is reproduction of measurement units, search for correspondences for field-specific national terms, as well as the specifics of genres and stylistic features of the text types in question. We conclude that the translator's role is primarily that of a mediator not only between languages, but also between cultures concerned. Therefore, a careful approach to the analysis of selected languages as well as cultures in a particular field is extremely important in order to provide an adequate translation of the original text.

Key words: technical text, localization, internationalization, technical data sheet, technical brochure.

Постановка проблеми. Дослідження особливостей перекладу технічних текстів $є$ актуальною темою, адже галузь науки і техніки перебуває в постійному розвитку. Інформація потребує постійного оновлення, а дослідники висвітлюють свою точку зору стосовно різноманітних аспектів технічного перекладу, що вимагає від нас порівняння i вибору найоптимальнішого варіанту перекладу для нашого дослідження. У технічних текстах міститься культурно-специфічна інформація, відтворення якої потребує особливої уваги і ретельного підходу до вивчення сфери застосування обраних типів тексту, якими $є$ технічні специфікації і технічні брошури.

Аналіз досліджень. Задля найточнішого відтворення культурно-специфічної інформації при перекладі технічних текстів необхідно обробити велику кількість інформації та обрати лише необхідне. Тому доцільно використовувати стратегію локалізації - «адаптацію продукту i супровідної технічної документації до умов прогнозованого ринку збуту» (Еррера Мендісабаль, 2017: 155-158). С. Гьопферіх зазначає, що «адекватне відтворення культурно-специфічної інформації $є$ невід'ємною частиною локалізації» і розділяє іiі на поверхневу та глибинну (Göpferich, 1995).

Поверхнева локалізація застосовується на мовному рівні і межує з перекладом, щодо глибинної, - вона використовується на рівні адаптації культурних відмінностей. Слід зауважити, що це тягне за собою інший спосіб подання інформації у тексті (Особливості перекладу інструкцій, 2020).

Мета статті - проаналізувати особливості відтворення культурно-специфічної інформації при перекладі технічних брошур і технічних специфікацій з англійської на українську мову. При цьому ми будемо спиратися на результати досліджень, які пропонують вирішення цієї проблеми на матеріалі інших мовних пар. Способи перекладу культурно-специфічних моментів у технічних текстах описали К. Райс та Г. Вермеєр у своїй спільній праці «Основи загальної теорії перекладу». Більша частина уваги приділена культурологічним і лінгвістичним аспектам загальної теорії перекладу. Згідно думки Г. Вермеєра, переклад мови оригіналу у відповідну форму мови перекладу є частиною ролі перекладача в міжкультурному спілкуванні.

Виклад основного матеріалу. Науково-технічний переклад - це частина процесу поширення інформації в міжнародному масштабі, що є необхідим для функціонування сучасного суспільства (Olohan, 2016).

Технічні тексти - це специфікації, інструкції, технічні брошури, керівництва 3 експлуатації, проекти, статті, технічні умови, доповіді, патентна документація (Byrne, 2006). Технічний текст є своєрідним керівництвом з використання інформації, що в ньому надається. Технічний переклад вимагає від перекладача наявності не тільки фонових знань, а й так званого «занурення» у світ обраної технічної сфери, адже необхідна неабияка обізнаність задля відтворення конкретних понять в технічному документі.

Не зважаючи на те, що основою технічних текстів $є$ загальнонаукові або вузькогалузеві терміни та наукові факти, не менш важливу роль відіграє й культурно-специфічна інформація, тому варто зосередити увагу на іiі різновидах. 
У роботі Ткач Г. С. і Кудрявцевої Н. С. наведено такі типи культурно-специфічної інформації (Ткач, Кудрявцева, 2019):

- абревіатури;

- одиниці вимірювання;

- жанрово-стилістичні особливості;

- технічні умови і національні стандарти.

Технічна специфікація - це «формалізований опис властивостей, характеристик і функцій об'єктів» (Шемшученко, 2003). Специфікація не $\epsilon$ обов'язковою, вона застосовується як додаток до наявного договору. Цей додаток надає можливість конкретизувати продукцію, що поставляється, їі точну кількість, окрім цього ретельно розписуються характеристики товару, а також зазначається ціна в одній або декількох різних валютах (Переклад специфікацій до договору, 2020). У випадку виникнення непорозумінь між замовником і постачальником стосовно договору за допомогою специфікації їх можна швидко вирішити, тому що саме у специфікації визначено чіткі параметри, які не підлягають обговоренню або оскарженню. Окрім цього, варто зауважити, що специфікація має бути складена таким чином, щоб не виникала можливість іiі різного потрактування, адже при судовому розгляді це може зашкодити одній зі сторін.

Ми дослідили більше 30 різноманітних технічних специфікацій від постачальників вітротурбін для вітроелектростанцій, а також проаналізували найнеобхідніші дані для вітровимірювальної техніки і виявили, що основним змістом цієї документації $\epsilon$ характеристика товару, а саме: кількість, властивості, рекомендації для використання, сума. Окрім цього, необхідно зазначити, що під час оформлення замовлення та перегляду специфікацій і технічних брошур, також варто враховувати властивості земельної ділянки, на якій розташовуватимуться вітроелектростанції, адже зазначені документи надають лише загальну інформацію про місце розміщення відповідного устаткування. Проаналізувавши технічні брошури різних представників вітровимірювального обладнання, ми повинні зауважити, що саме у технічних брошурах наявні більш конкретні відомості про вітровимірювальні прилади, наприклад, про датчики, флюгери, щогли та способи установки обладнання.

Складнощі при перекладі специфікацій полягають також у перекладі термінів. Наприклад, термін offset перекладається як отвір у текстах, що застосовуються у сфері машинобудування, а от у будівництві - як відхилення, перехідна ланка, у металургії - це зміщення, у комп'ютерній тех- ніці - неузгодженість, розрегулювання. Окрім досить складних термінів, застосовуються і прості: quantity - кількість; name - назва; sum - сума.

Наявність або відсутність деяких аспектів у специфікації напряму залежить від специфіки договору. Тому варто зосереджувати увагу на тематиці основного документу та його додатків. Ми проаналізували договори, укладені між двома компаніями, що займаються вітровимірювальною технікою та зробили висновок, що майже всі специфікації містять спільну інформацію тільки 3 різними показниками, яка характеризує обладнання, що доставляється. Технічна брошура дає змогу у короткий термін ознайомитися 3 основними аспектами діяльності компанії з технічної точки зору. Задля детальнішого ознайомлення 3 приладами, що надаються, необхідно переглянути всі розділи брошури і проаналізувати конкретні аспекти стосовно окремих деталей. Саме через велику кількість деталей вітровимірювального обладнання нам необхідно приділити неабияку увагу термінології вітроелектростанцій, складовим вітряків, вітротурбін, щогл та свай задля зведення станцій, а також перекладу метеорологічних показників.

Дуже важливим аспектом при перекладі технічних брошур i специфікацій $\epsilon$ дотримання формату документу, який створюється цільовою мовою. Окрім цього, необхідно дотримуватися певної термінології, яка б відповідала міжнародним або національним стандартам. Стосовно цих стандартів варто зазначити, що дуже важливим $€$ перевірка відповідності технічних умов i національних стандартів законодавству країни, мовою якої виконується переклад, адже існує різна класифікація для кожної країни. Наприклад, необхідного терміна може взагалі не існувати в мові перекладу, у такому випадку перекладачеві доцільно застосовувати пояснювальну примітку. Основними перекладацькими трансформаціями, які застосовуються при перекладі є вилучення та додавання, залежно від власне документу. Вилучення використовується задля скорочення інформативної надмірності, частіше у специфікаціях, які потребують відтворення конкретної інформації $з$ технічного напряму. А додавання здебільшого використовується при перекладі технічних брошур задля того, аби якомога більше скоротити відмінності в граматичних часових формах англійської та української мови і передати значення, яке найточніше відтворить текст оригіналу.

Досліджуючи типи локалізацій, ми дійшли висновку, що локалізація вимагає:

- відповідності стилю замовника; 
Акімова А., Кудрявцева Н. Відтворення кумьтурно-специфічної інформації...

- правильного застосування норм і правил мови перекладу;

- дотримання вказаної термінології, або якщо вона відсутня, виконання перекладу відповідно до галузевих стандартів і термінології культуриреципієнта;

- дотримання термінології замовника;

- послідовності у використанні перекладних термінологічних одиниць;

- дотримання форматів документів, створених цільовою мовою;

- технічної грамотності.

Прикладами поверхової локалізації є адаптація одиниць іноземної метричної системи до національної, подання дат, часу та чисел в тексті перекладу в тій формі, що є конвенційною в межах культури-реципієнта.

Щодо одиниць вимірювання, то доречним буде зауважити, що застосовувати їх у тексті необхідно відповідно до усталеної метричної системи.

Під час перекладу специфікацій здебільшого користуються такою таблицею основних одиниць вимірювання (Byrne, 2012: 156):

\begin{tabular}{|l|c|l|c|}
\hline \multicolumn{4}{|l|}{ Base Units } \\
\hline Name & $\begin{array}{c}\text { Unit } \\
\text { symbol }\end{array}$ & \multicolumn{1}{|c|}{ Quantity } & $\begin{array}{c}\text { Symbol for } \\
\text { Quantity }\end{array}$ \\
\hline Metre & $\mathrm{m}$ & length & $\mathrm{l}$ \\
\hline Kilogram & $\mathrm{kg}$ & mass & $\mathrm{m}$ \\
\hline Second & $\mathrm{s}$ & time & $\mathrm{t}$ \\
\hline Ampere & $\mathrm{A}$ & electric current & $\mathrm{l}$ \\
\hline Kelvin & $\mathrm{K}$ & $\begin{array}{l}\text { thermodynamic } \\
\text { temperature }\end{array}$ & $\mathrm{T}$ \\
\hline Candela & $\mathrm{cd}$ & luminous intensity & $\mathrm{lv}$ \\
\hline Mole & $\mathrm{mol}$ & amount of substance & $\mathrm{n}$ \\
\hline
\end{tabular}

Проте, для доцільного відтворення повного обсягу технічної інформації, що міститься у специфікаціях, цього недостатньо. Дуже часто використовується така одиниця вимірювання, як дюйм («inch», позначення - '). Це англійська одиниця вимірювання довжини, тому перекладачу необ- хідно віднайти правильний відповідник у цільовій мові або ж конвертувати величину згідно 3 міжнародною системою SI (2,54 см).

Окрім цього, існують деякі пункти, відтворення яких підлягає певним загальноприйнятим нормам, наприклад (Еррера Мендісабаль, 2017: 155-158):

- надання інформації щодо часу відповідно до середньоєвропейського стандарту, а саме у 24-годинному форматі (UTC=Universal Time Coordinator);

- уникнення вживання неусталених скорочень, модних слів, сленгу;

- подання номерів телефонів згідно з міжнародними стандартами (з міжнародним кодом країни та регіону);

- подання грошових одиниць із зазначенням суми в національній валюті;

- вживання дат в усталеній формі згідно 3 нормами ISO 8601.

Висновки. Підсумовуючи зазначене вище, можемо констатувати, що стилю технічної брошури та специфікації притаманні: точність, нейтральний тон викладу змісту, стислість, документальність. Під час перекладу технічних брошур та специфікацій дуже важливо адекватно передавати культурноспецифічну інформацію, наприклад, одиниці вимірювання, національні стандарти, часові формати.

Для технічних текстів характерними є культурно-специфічні відмінності, що зумовлюються різними економічними, географічними, історичними причинами. Таким чином, перекладач повинен бути обізнаним не тільки з термінологією, а й 3 культурними особливостями країни-постачальника певної продукції, товарів або обладнання. Перекладач виступає посередником не тільки між мовами, але й між певними культурами. Тому знання історії, культури, географії, побуту народу, що безпосередньо або опосередковано репрезентується в тексті оригіналу, для спеціаліста у сфері перекладознавства дуже необхідне при перекладі технічної документації.

\section{СПИСОК ВИКОРИСТАНИХ ДЖЕРЕЛ}

1. Еррера Мендісабаль А. В. Особливості відтворення культурно-специфічної інформації в технічних текстах. Наукові записки НДУ ім. М. Гоголя. Серія «Філологічні науки». С. 155-158.

2. Особливості перекладу інструкцій: веб-сайт. URL: https://ukrreferat.com/chapters/inozemna-mova/osoblivostiperekladu-instruktsij.html (дата звернення: 08.02.2021)

3. Переклад специфікацій до договору: веб-сайт. URL: https://azbuka-bp.com.ua/uk/perevod-specifikacii-k-dogovoruukr.html (дата звернення: 08.02.2021)

4. Специфікація. Юридична енциклопедія: у 6 т. / за ред. Ю. С. Шемшученко. Київ: Українська енциклопедія ім. М. П. Бажана, 2003. Т. 5. С. 736.

5. Ткач Г. С., Кудрявцева Н. С. Особливості відтворення культурно-специфічної інформації під час перекладу технічних інструкцій з англійської мови українською. Науковий вісник Міжнародного гуманітарного університету. Сер. Філологія. 2019. № 43(5). С. 148-151.

6. Byrne J. Scientific and technical translation explained. London \& New York: Routledge, 2012. 229 p. 
7. Byrne J. Technical translation. Usability strategies for translating technical documentation. Dordrecht: Springer, 2006. 208 p.

8. Göpferich S. A Pragmatic Classification of LSP Texts in Science and Technology, Target 7, 1995. 305-326 p.

9. Olohan M. Scientific and technical translation. London \& New York: Routledge, 2016. 253 p.

\section{REFERENCES}

1. Errera Mendisabal A.V. Osoblyvosti vidtvorennia kulturno-spetsyfichnoi informatsii $\mathrm{v}$ tekhnichnykh tekstakh. [Features of reproduction of culturally specific information in technical texts]. Scientific notes of NDU named after M. Gogol. Philological Sciences Series. 155-158 p. [in Ukrainian]

2. Features of translation of instructions: web-site. Reach via URL: https://ukrreferat.com/chapters/inozemna-mova/ osoblivosti-perekladu-instruktsij.html (Date of access: 08.02.2021) [in Ukrainian]

3. Translation of specifications to the contract: web-site. Reach via URL: https://azbuka-bp.com.ua/uk/perevodspecifikacii-k-dogovoru-ukr.html (Date of access: 18.01.2021)

4. Spetsyfikatsiia. Yurydychna entsyklopediia [Specification. Legal Encyclopedia]: in 6 volumes / ed. Yu. S. Shemshuchenko. Kyiv: Ukrainian encyclopedia named after M. P. Bazhana, 2003. V. 5. 736 p. [in Ukrainian]

5. Tkach G. S., Kudriavtseva N. S. Osoblyvosti vidtvorennia kulturno-spetsyfichnoi informatsii pid chas perekladu tekhnichnykh instruktsii z anhliiskoi movy ukrainskoiu. [Features of reproduction of culturally specific information during the translation of technical instructions from English into Ukrainian]. Scientific Bulletin of the International Humanities University. Series: Philology. 2019. No. 43 (5). 148-151 p. [in Ukrainian]

6. Byrne J. Scientific and technical translation explained. London \& New York: Routledge, 2012. 229 p.

7. Byrne J. Technical translation. Usability strategies for translating technical documentation. Dordrecht : Springer, 2006, $208 \mathrm{p}$.

8. Göpferich S. A Pragmatic Classification of LSP Texts in Science and Technology, Target 7, 1995. 305-326 p.

9. Olohan M. Scientific and technical translation. London \& New York: Routledge, 2016. 253 p. 